\title{
Ist die Politik der Troika undemokratisch?
}

\author{
WOLFGANG MERKEL
}

$D$ ie Fakten sind bekannt. Seit dem Ausbruch der Finanz- und wenig später der Eurokrise erlebt Griechenland die dramatischste Wirtschaftskrise Westeuropas seit 1950. Die Arbeitslosigkeit stieg von 7,8\% im Jahr 2008 auf 27,5\% (2013); die Jugendarbeitslosigkeit beträgt das Doppelte. Das Wachstum brach in den fünf Jahren nach Ausbruch der Krise um 29 \% ein, der Mindestlohn wurde um ein Viertel gekürzt. Die desaströsen Kennziffern könnten fortgesetzt werden und deuten doch die soziale Katastrophe nur an.

Die Auslöser der Krise sind vielfach: riskante Kreditgeschäfte der Banken, die Blase auf dem Immobilienmarkt, die Spekulation gegen den Verbleib Griechenlands im Euro, selbstherrliche nordamerikanische Rating-Agenturen, der failing tax state, den die Griechen selbst zu verantworten haben, die erschlichene Aufnahme Griechenlands in die Wirtschafts- und Währungsunion, das Zögern der deutschen Regierung, Griechenland in der Eurokrise Unterstützung zuzusagen, und das Austeritätsprogramm der Kreditgeber, das Griechenland in die Depression trieb. Das von der Troika und den deutschen Bundesregierungen oktroyierte Sparprogramm war und ist ein wirtschaftliches Desaster. Aber ist es auch undemokratisch?

Nimmt man einen verfassungstheoretischen Standpunkt ein, ließe sich folgendermaßen argumentieren. Ein Mitglied der Eurozone gerät in finanzielle Turbulenzen und fragt bei den europäischen Institutionen Kredite nach, die ihm private Kreditmärkte mangels Bonität verweigern. Der IWF, die Kommission und die EZB handeln die Kreditbedingungen aus. Die Konditionen sind hart, unsolidarisch und ökonomisch desaströs. Niemand, so das formaldemokratische Argument, zwingt Griechenland, diese Bedingungen anzunehmen. Das griechische Parlament ist souverän und kann die Kredite wie ihre Bedingungen ablehnen. Bisher hat das Parlament in Athen aber noch jedes Hilfspaket angenommen. Selbst die herrisch auftretenden Emissäre der Troi$k a$, die tief in die Haushalts-, Sozial- und gar Lohnpolitik des Landes eingreifen, könnten mit einem einfachen Parlamentsbeschluss aus dem Land geschickt werden. Das ist bisher nicht geschehen. Regierung und Parlament schätzen die unwägbaren Kosten eines möglichen Austritts des Landes aus dem Euro höher ein als den Schaden, den die Sparpolitik anrichtet. Die Politik der EU ist unsolidarisch, im Verfassungssinne undemokratisch ist sie nicht.

Das ist aber noch nicht die ganze Geschichte. Sie lässt sich auch anders schreiben und dies mit guten demokratischen Argumenten. In parlamentarisch-repräsentativen Demokratien wählen die Bürger ihre Abgeordneten und diese die Regierung. Beide sollen gemäß ihrer programmatischen Versprechen die Interessen und Präferenzen ihrer Wähler durchsetzen. Sind die Bürger mit der Politik nicht zufrieden, können sie die Regierung abwählen. In Griechenland, Spanien und Portugal haben die Wähler in der Krise mehrfach ihre Regierungen ausgewechselt. Diese haben aber stets die gleichen Austeritätspolitiken exekutiert wie ihre Vorgängerinnen. Die Bürger konnten wählen, hatten aber keine Wahl. Demokratische Wahlen werden bedeutungslos, wenn sie nicht unterschiedliche Politiken ermöglichen. Das ist das Damoklesschwert der Postdemokratie, das nicht nur über Südeuropa hängt.
Nun ist Ende 2014 Unerhörtes geschehen. Die Griechen haben eine linkssozialistische Regierung mit einem nationalistischen Juniorpartner gewählt. Der Kern beider Wahlprogramme war die Ablehnung des „Diktats“der Troi$\mathrm{ka}$. Seitdem verhandeln beide Seiten, auch mit symbolischen Tritten unterm Konferenztisch. Noch ist nicht erkennbar, ob Syriza viel mehr erreichen wird als seine korrupten Vorgängerregierungen. Es wird darauf ankommen, dass die Troika der demokratisch legitimierten Regierung mehr Spielräume einräumt. Sonst werden sich die Verantwortlichen den Vorwurf gefallen lassen müssen, dass sie sich als neokoloniale Kreditgeber daran beteiligen, demokratische Regierungen auszuhöhlen. Vielleicht hat die Kanzlerin das gemeint, als sie von marktkonformen Demokratien sprach.

Die demokratische Geschichte ist damit allerdings noch nicht zu Ende. Denn auch die Regierungen der Kreditländer sind demokratisch gesehen nichts anderes als die Repräsentanten ihrer Bürger. Sie sind verpflichtet, im Auftrag ihres Demos zu handeln. In Deutschland suggerieren uns Umfragen, dass eine übergroße Mehrheit Kredite und Garantien an Griechenland nur dann billigt, wenn sie mit strengen Sparauflagen verbunden sind. Die Kanzlerin erweist sich aus dieser Perspektive wieder einmal als lupenreine Demoskopie-Demokratin. Als Kanzlerin ist sie allerdings laut Verfassung angehalten, Schaden vom deutschen Volk abzuwenden, auch wenn das gegen die Überschriften der Bildzeitung verstößt. Gehen die deutsche Regierung und die Troika weiter so rabiat mit der Souveränität schwächerer Staaten in Europa um, werden sie längerfristig manche europäischen Völker gegen den germanischen Praeceptor Europae aufbringen.

Aber auch hier endet die Geschichte noch nicht. So tief die Eurokrise auch ist, hinter ihr verbirgt sich ein noch grundsätzlicheres Problem: die innere Verfasstheit der Europäischen Union. Die EU hat den europäischen Bürgern viele wirtschaftliche, kulturelle, ja sogar politische Freiheiten gebracht. Sie hat aber zwei gewichtige Nachteile: Sie ist zum einen weniger demokratisch organisiert als ihre Mitgliedstaaten, zum anderen hat sie den Handlungsspielraum demokratischer Entscheidungen gegenüber den Märkten weiter eingeschränkt. Es birgt deshalb eine grundsätzliche Problematik, wenn von den demokratischeren Nationalstaaten Kompetenzen an eine supranationale Union abgegeben werden, die von Parlamenten wenig kontrolliert wird, die Partizipation der Bürger kaum kennt, den Wirtschaftslobbys besondere Macht einräumt und wenn von einer europäischen Öffentlichkeit nicht die Rede sein kann. Bisher war jede Machtabgabe an die Europäische Union auch ein Wechsel auf eine demokratischere Zukunft, der stets geplatzt ist.

WOLFGANG MERKEL, Prof. Dr., ist Direktor der Abteilung "Demokratie und Demokratisierung" am Wissenschaftszentrum Berlin für Sozialforschung (WZB) und Professor an der Humboldt-Universität zu Berlin. Arbeitsschwerpunkte: politische Regime, Demokratie, Sozialdemokratie und soziale Gerechtigkeit.

wolfgang.merkel@wzb.eu 